\title{
Low background mould-prepared gelatine standards for reproducible quantification in elemental bio-imaging
}

Received 00th January 20xx, Accepted 00th January 20xx

DOI: $10.1039 / \times 0 \times x 00000 x$

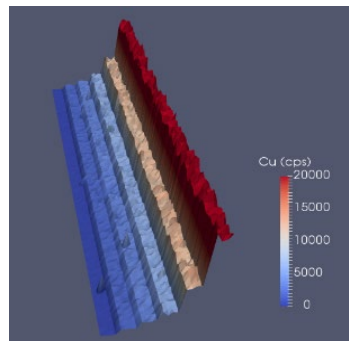

Graphical abstract: Raw intensities obtained from the ablation of mould-prepared gelatine.

\author{
Mika T. Westerhausen ${ }^{a^{\dagger}}$, Thomas E. Lockwood ${ }^{a^{\dagger}}$, Raquel Gonzalez de Vega ${ }^{\mathrm{a}}$, Anna Röhnelt ${ }^{\mathrm{b}}$ \\ David P. Bishop ${ }^{a}$, Nerida Colec, Philip A. Doble ${ }^{a}$ and David Clases ${ }^{a *}$
}

\begin{abstract}
Standard preparation for elemental bioimaging by laser ablation-inductively coupled plasma-mass spectrometry is confounded by the chemical and physical differences between standard and sample matrices. These differences lead to variable ablation, aerosol generation and transportation characteristics and must be considered when designing matrixmatched standards for reliable calibration and quantification. The ability to precisely mimic sample matrices is hampered due to the complexity and heterogeneity of biological tissue and small variabilities in standard matrices and sample composition often negatively impact accuracy, precision and robustness. Furthermore, cumbersome preparation protocols may limit reproducibility and traceability. This work presents novel facile methods for the preparation of gelatine standards using both commercial and laboratory-made moulds. Surface roughness, thickness and robustness of the mould-prepared standards were compared against cryo-sectioned gelatine and homogenised brain tissue standards. The mould-prepared standards had excellent thickness accuracy and signal precision which allowed robust quantification, were easier to prepare and therefore easier to reproduce. We also compared gelatine standards prepared from a variety of animal sources and discuss their suitability to calibrate low level elemental concentrations. Finally, we present a simple method to remove background metals in gelatine using various chelating resins to increase the dynamic calibration range and to improve limits of analysis.
\end{abstract}

\section{Introduction}

Laser ablation-inductively coupled plasma-mass spectrometry (LA-ICP-MS) was first applied to biological tissues in 1994 by Wang et al. ${ }^{1}$ and is now a routine technique to measure the spatial distribution of elements and co-factors of functional biomolecules. Recent advances in immunohistochemistry have expanded the applicability of LA-ICP-MS to the qualitative and quantitative investigation of biomolecule distributions ${ }^{2,3}$. Internal standardisation approaches 5,6 to overcome instrumental drifts as well as progress in sampling techniques ${ }^{4}$ have contributed to improved precision and accuracy and rapid analyses ${ }^{7}$. LA-ICP-MS is often considered the gold standard for spatial quantification of elements in biological tissues due to its high dynamic range and species- and matrix-independent ionisation and detection.

However, consistent ablation with a pulsed laser is dependent on the matrix of the standard and specimen, and internal standardisation is difficult. Instrumental drift also influences quantification, which becomes particularly pronounced when

\footnotetext{
a. The Atomic Medicine Initiative, University of Technology Sydney, Broadway, New South Wales, Australia

b. Institute of Inorganic and Analytical Chemistry, University of Muenster

c. ARC Training Centre in Biodevices, Faculty of Science, Engineering and

Technology, Swinburne University of Technology, Hawthorn, Victoria, Australia

here.

+ These authors contributed equally

*Corresponding author, Email: David.Clases@uts.edu.au
}

long acquisition times are required ${ }^{6,8}$. The quantification of biomolecules is even more challenging and requires careful characterisation of the labelled bio-probes ${ }^{9}$. Nevertheless, spatially resolved quantification provides invaluable insights into biological processes and has encouraged extensive investigations of accurate calibration and quantification and produced a variety of methods and protocols 7,10 .

Most approaches suggest matrix-matching to simulate the biological, chemical and physical environment of metals and heteroatoms to guarantee consistent ablation characteristics, aerosol formation, transport, atomisation and ionisation ${ }^{7,15}$. However, the application of matrix-matched tissue standards is limited as the resulting matrices cannot fully mimic the full spectrum of biological tissue in terms of heterogeneity, durability and biochemical environment. Ad-hoc efforts to match complex physical and biochemical features often result in batches of standards with unique characteristics which are difficult to reproduce.

External calibration is the most frequently applied calibration technique performing sequential and repeated analysis of available reference materials and samples for validated quantification. The diversity and individuality of biological tissues often preclude the use of certified reference materials or standards, and laboratories are required to prepare and characterise custom made reference standards ${ }^{11-14}$.

One common approach to prepare reference standards includes the homogenisation of easily obtainable tissues from lamb, pig, cow or mouse to match the target tissue. The 
homogenate is spiked with aliquots of elements, again homogenised, frozen and subsequently sectioned to their desired thickness. A cross-quantification step consisting of digestion of the standard and analysis by solution nebulisation ICP-MS is required to determine accurate elemental concentrations ${ }^{11}$. A variety of approaches have been published reporting the preparation of materials to simulate tissues like brain $^{14,16}$, eye ${ }^{17,18}$, tumour tissue ${ }^{3,13,19}$, liver ${ }^{20,21}$ and teeth ${ }^{22}$. While many of these approaches and protocols are reliable for quantification for a defined set of samples, a single universal absolute quantification method for LA-ICP-MS is virtually impossible.

The natural abundance of endogenous elements in the chosen matrix of the standard also limits the ability to measure elements at lower concentrations. Trace elements that may be downregulated by a biological response are therefore often outside the calibration range when reference tissues exhibiting a natural abundance of elements are used. Furthermore, homogenisation changes the tissue's physical properties and cutting processes increase the uncertainty between batches of standards, potentially introducing systematic errors. Specifically, the operation of micro- and cryotomes can induce deformation and dimensional changes in thickness as discussed by Dorph-Petersen et al. ${ }^{23}$. Standards originating from different tissues and/or different animals (even within the same species) show distinct characteristics which can be traced back to natural variations in individual elemental and biomolecule levels influenced by genetics, environment and type of tissue. The tedious preparation and characterisation, and the susceptibility towards systematic errors has encouraged investigations of other standard materials which are easier to manufacture, offer improved traceability and show less variability.

Hydrocolloid gel-based materials such as gelatine-based standards are becoming increasingly popular for the calibration of elements in biological tissues as similarities in their composition mitigate the problems associated with homogenates from raw animal tissues ${ }^{15,24-26}$. Three major methods for the fabrication of gelatine standards are described in literature: pipetted films ${ }^{27}$, spotted droplets ${ }^{24}$ and cryosections ${ }^{28}$. However, surface tensions, "coffee-stain" effects, elemental discrimination and cutting artefacts may affect the homogeneity of elemental distribution and standard topography. These factors need to be carefully controlled to sustain accurate and precise quantification ${ }^{24}$. Furthermore, trace analyses may be limited as for animal tissue; also gelatine has measureable natural background levels for biologically important metals, complicating quantification in some cases. The properties of gelatine standards can be controlled quite precisely by several parameters. Šala et al. discussed the effect of various drying/setting and gelatine content in the context of coffee-stain effects and elemental discrimination. They analysed thickness and surface distributions at various lateral resolutions and found that careful control allows the fabrication of highly homogenous, microanalytical standards suited for the calibration of elements in soft biological tissue ${ }^{24}$.
Complete ablation of the entire sample requires the standard to have the same thickness as the sample and is usually accomplished by cutting with a micro- or cryotome. However, these instruments are a potential source for lower accuracy and precision, even when calibrated regularly ${ }^{23}$. Another standardisation approach is to avoid complete ablation of sample and standard in order to leave some remaining tissue on the microscope slide. If matrix-matching was successful, continuous amounts of material should be ablated from both sample and standards.

In this work, we present novel, facile methods for the preparation of gelatine standards for improved quantification compared to cryo-cut gelatine and homogenates from raw animal tissue. We demonstrate that commercial and laboratory-made moulds offer improved, simplified and reliable control of standard dimensions and surfaces. Physical and chemical homogeneity of selected samples, tissue standards and differently prepared gelatine standards are discussed in the context of robustness and reproducibility. Furthermore, we discuss the effect of endogenous element concentrations on the analytical figures of merit, compare different gelatine materials and present an extraction method to mitigate high elemental background intensities, improving current limits of analysis.

\section{Experimental}

\section{Animal tissue preparation}

Male mouse C57/BI6 lungs were harvested under Animal Care and Ethics protocol number 15-104-FINMH at the Florey Institute of Neuroscience and Mental Health (Melbourne, Australia). Briefly, animals were euthanised with an overdose of sodium pentobarbitone $\left(100 \mathrm{mg} \mathrm{kg}^{-1}\right)$ and perfused with $30 \mathrm{~mL}$ of warmed $\left(37^{\circ} \mathrm{C}\right) 0.1 \mathrm{M}$ phosphate buffered saline (PBS), $\mathrm{pH} 7.4$.

Male wild-type (C57BL/6J) muscle tissues were purchased from Jackson Laboratories (Bar Harbor, ME, USA,) and the quadriceps muscle was dissected under guidelines established by the Institutional Animal Care and Use Committee at the University of California, Los Angeles (ARC \#2000-029-61D).

Mouse brain standards were prepared as previously described by Hare et al. ${ }^{11}$ using mouse tissues harvested from control animals which were euthanised under a material transfer agreement between the Florey Institute and the University of Technology Sydney.

For the preparation of homogenised mouse brain standards, brains were fixed in 4\% paraformaldehyde in PBS and frozen at $-80{ }^{\circ} \mathrm{C}$ for storage. For further treatment, tissues were thawed, homogenised and weighted aliquots were spiked with metal solutions $\left(\mathrm{Mn}, \mathrm{Cu}, \mathrm{Zn}\right.$ at $0,5,10,25$ and $50 \mu \mathrm{g} \mathrm{m}^{-1}$, respectively). The spiked homogenate was filled in moulds and frozen at $-20{ }^{\circ} \mathrm{C}$. The frozen homogenate was cryo-sectioned using PTFE-coated cryotome blades (DT315R50 Silver Microtome Blades. C. L. Sturkey, Inc., Lebanon PA) on a cryotome (CryoStar ${ }^{\mathrm{TM}}$, Thermo Fisher Scientific, North Ryde, NSW, Australia) and mounted on microscope glass slides 

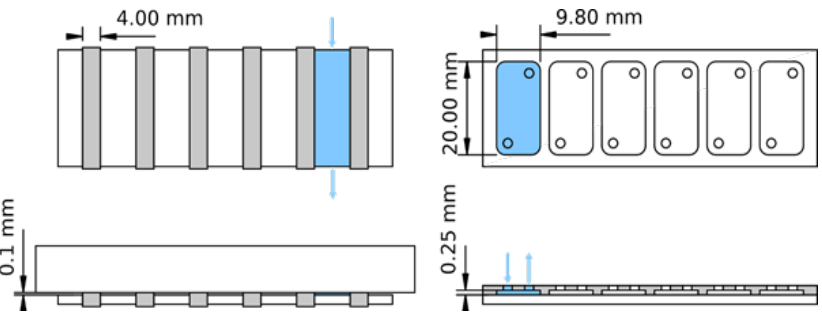

Figure 1: A: Schematic of a HybriWell ${ }^{\mathrm{TM}}$ sealing system which was used as (commercial) mould. Filling the mould with a $10 \%$ heated (liquid) gelatine produces $25 \mu \mathrm{m}$ thick standards after drying. B: Schematic for the fabrication of laboratorymade moulds. Different thicknesses may be tailored to the desired thickness using multiple layers of Teflon tape or by varying the gelatine content.

(Superfrost ${ }^{\mathrm{TM}}$, Thermo Fisher Scientific, North Ryde, NSW, Australia). Cross quantification was performed on a $7500 \mathrm{cx}$ series ICP-MS (Agilent Technologies, Mulgrave, Australia) equipped with a micromist ${ }^{\mathrm{TM}}$ concentric nebuliser (Glass Expansion, West Melbourne, Australia) and a Scott type double pass spray chamber cooled to $2{ }^{\circ} \mathrm{C}$ for sample introduction. Helium was employed as collision/reaction gas to reduce spectral interferences. Calibration was performed using MassHunter B.05.00 software (Agilent Technologies). Calibration standards for ICP-MS, 67-70\% nitric acid (Seastar Baseline) for acidification (1\%) as well as $30-32 \% \mathrm{H}_{2} \mathrm{O}_{2}$ (Seastar Baseline) for tissue digestions were obtained from Choice Analytical (Thornleigh, NSW, Australia). For cross quantification, aliquots (approximately $50 \mathrm{mg}$ ) of spiked tissue homogenate were weighed and digested in a Milestone ML1200 microwave digester (In Vitro Scientific, Noble Park North, Victoria, Australia) in $4 \mathrm{~mL}$ concentrated nitric acid and $1 \mathrm{~mL} \mathrm{H} \mathrm{H}_{2}$ and subsequently diluted. Recovery was measured following the digestion of BCR185R (bovine liver). All tissue standards were analysed in triplicate to calculate averages and standard deviations.

\section{Gelatine tissue preparation}

Various gelatine made from bovine bone, porcine skin and cold fish were purchased from Sigma Aldrich (Castle Hill, NSW, Australia) and gelatine made from calf skin from Polysciences, Inc. (Warrington, PA). To maintain the integrity of the gelatine, the $\mathrm{pH}$ was controlled by buffering and using metal salt solutions without nitric acid. $100 \mathrm{mg}$ of each gelatine was dissolved in $1000 \mu \mathrm{L}$ of buffer solution, which comprised $100 \mathrm{mM}$ Tris- $\mathrm{HCl}$ buffer (pH 7.4), $10 \mathrm{mM}$ EDTA, 1\% w/w polyethylene glycol $\left(M_{n} 400\right)$ prepared in Milli-Q water (18.2 $\mathrm{M} \Omega \cdot \mathrm{cm}^{-1}$ at $25^{\circ} \mathrm{C}$, Arium Pro Vf, Sartorius, Goettingen, Germany). The buffer was essential to sustain the integrity of the gelatine at higher metal concentrations. Nitrate hydrate salts of $\mathrm{Mn}, \mathrm{Cu}$ and $\mathrm{Zn}$ were diluted with the buffered solution and spiked into the gelatine solution at concentrations of 0,1 , $5,10,15$ and $30 \mu \mathrm{g} \mathrm{mL}-1$, respectively.

Commercial Grace Bio-Labs HybriWell ${ }^{\mathrm{TM}}$ sealing systems $(50 \mu \mathrm{L}$, $9.8 \mathrm{~mm} \times 20 \mathrm{~mm} \times 0.25 \mathrm{~mm}$, Sigma Aldrich) were used with microscope slides to manufacture $25 \mu \mathrm{m}$ thick gelatine standards. Gelatine was heated to $54{ }^{\circ} \mathrm{C}$ until liquid then pipetted into a pre-heated mould as illustrated in Fig. 1 (right) and immediately frozen at $-20^{\circ} \mathrm{C}$ for $15 \mathrm{~min}$. The mould was removed, and the frozen gelatine standards were stored at room temperature overnight for drying. While freezing was vital to obtain homogeneous elemental distributions and to remove the mould without damaging the standard, longer freezing times were found to induce cryo-artefacts such as holes and uneven surfaces. The final thickness of the standards was $25 \mu \mathrm{m}$ as drying reduced the mass and thickness of the standards 10 fold. The scheme and preparation process is shown in Fig. 1 (A). For cross-quantification of standards, liquid gelatine was pipetted in polypropylene tubes and weighed after drying overnight. Digestion was achieved shaking the solidified gelatine aliquot in $1 \mathrm{~mL}$ of $20 \%$ nitric acid for 20 minutes followed by dilution. All gelatine standards were analysed in triplicate to calculate averages and standard deviations. Various gelatine standards thicknesses were produced with laboratory prepared moulds by using commercial Teflon tape (Bush branded) $(100 \mu \mathrm{m})$ as a spacer between a PTFE block and glass microscope slide. The resulting gaps were filled from the side with heated liquid gelatine as shown in Fig. 1 (left) and subsequently frozen and dried as per the commercial moulds. The Teflon tape was $4 \mathrm{~mm}$ wide which avoided standard cross contamination. Multiple layers of the $100 \mu \mathrm{m}$ Teflon tape could be used to manufacture gelatine standards with thicknesses of any multiple of $10 \mu \mathrm{m}$ and the thickness could further be controlled by varying the gelatine content.

\section{Topography characterisation}

Brain tissue samples were homogenised and cryosectioned at $10 \mu \mathrm{m}$. After cryo-sectioning, thickness and surface topography were compared against those of the gelatine standards and representative samples using a DektaXT Profilometer (Bruker, Billerica, MA) operated at room temperature $\left(25^{\circ} \mathrm{C}\right)$. Gelatine standards were kept overnight to allow drying to ensure repeatable 10 -fold thickness reduction. A $2 \mu \mathrm{m}$ stylus with a force of $1 \mu \mathrm{N}$ was used to scan standards with a lateral resolution of $0.33 \mu \mathrm{m}$ over the full lengths of the standards.

\section{Elemental extraction to decrease background levels}

Naturally abundant elements were removed from the gelatine via solid-liquid extraction with non-buffered water to avoid buffer components interfering with the extraction. $200 \mathrm{mg}$ of gelatine was weighed and dissolved in $1000 \mu \mathrm{L}$ of water, heated to $54{ }^{\circ} \mathrm{C}$, and spiked with chelating resins. Various resins were investigated: Amberlyst $15(\mathrm{H})$, Amberlite CG50 (H) and Amberlite IR120 ( $\mathrm{Na}$ ) were purchased from Sigma Aldrich and Bio-Rex 70 and Chelex 100 were purchased from Bio-Rad (Gladesville, Australia). The resins were added to liquid gelatine standards and gently shaken for 1 hour before being separated by centrifugation in a Centrifuge 5702 (Eppendorf; Macquaire Park, Australia) operated at $2000 \mathrm{rpm}$ for 2 minutes. The supernatant was diluted with a $2 x$ concentrated buffer solution to produce a $10 \%$ buffered gelatine standard, which was then filled into the mould. 


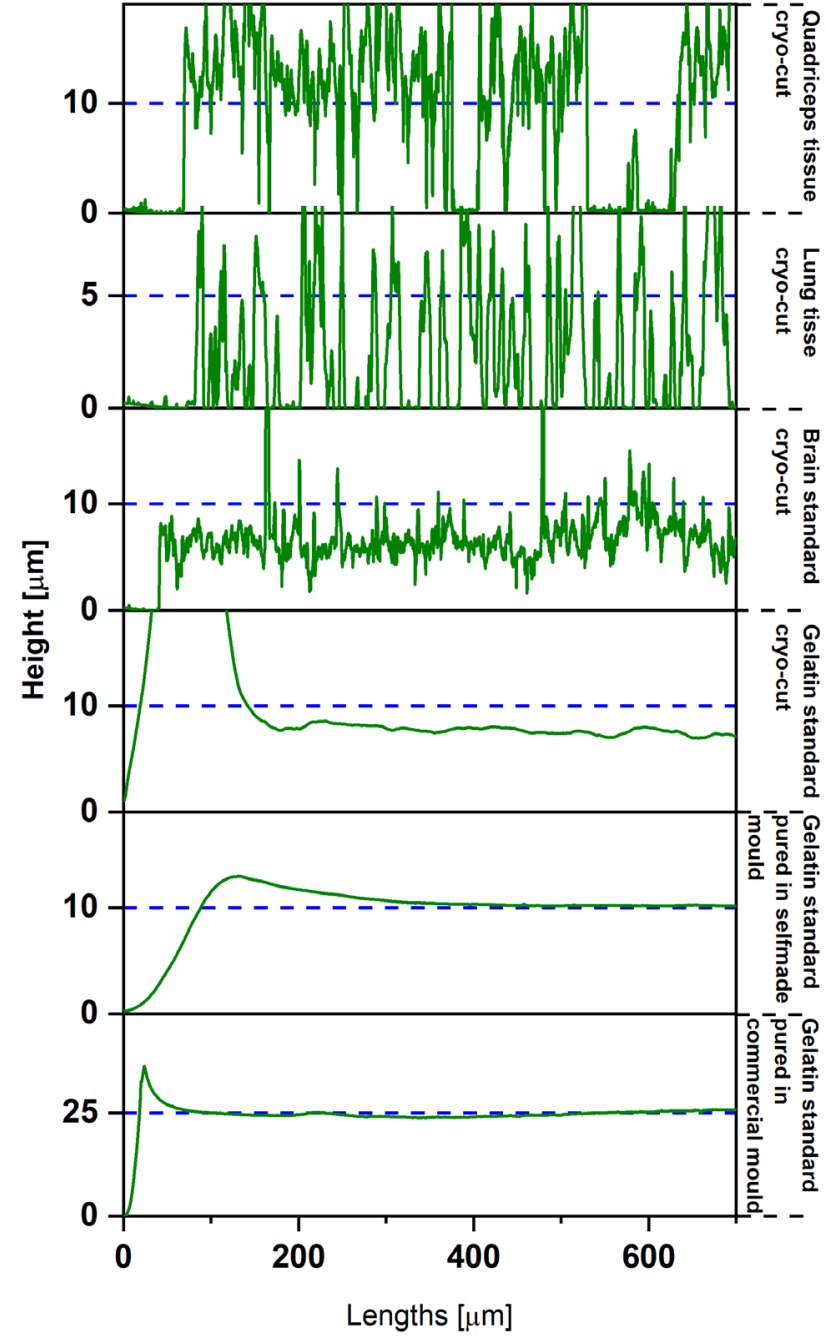

Figure 2: The heights of standards and samples were determined by profilometry to show deviations from expected heights and heterogeneity in surface topography. The blue dashed line indicates the expected thickness and the green line represents the actual height.

Table 1: Comparison of accuracy derived from different preparation methods and materials. Values were calculated from profilometry data avoiding the standards edges which were subject to drying artefacts.

\begin{tabular}{|c|c|c|c|c|}
\hline Standard type & $\begin{array}{c}\text { Theoretical } \\
\text { thickness } \\
{[\mu \mathrm{m}]}\end{array}$ & $\begin{array}{c}\text { Observed } \\
\text { thickness } \\
{[\mu \mathrm{m}]}\end{array}$ & $\begin{array}{c}\text { Height } \\
\text { deviation } \\
{[\%]}\end{array}$ & $\begin{array}{c}\text { Standard } \\
\text { deviation } \\
{[\mu \mathrm{m}]}\end{array}$ \\
\hline $\begin{array}{l}\text { Quadriceps sample } \\
\text { (cryo-cut) }\end{array}$ & 10.00 & 12.64 & +26.4 & $\begin{array}{c}6.68 \\
(52.8 \%)\end{array}$ \\
\hline $\begin{array}{l}\text { Lung sample } \\
\text { (cryo-cut) }\end{array}$ & 5.00 & 2.59 & -51.0 & $\begin{array}{c}2.82 \\
(108.9 \%)\end{array}$ \\
\hline $\begin{array}{l}\text { Brain standard } \\
\text { (cryo-cut) }\end{array}$ & 10.00 & 6.73 & -33.7 & $\begin{array}{c}3.52 \\
(52.3 \%)\end{array}$ \\
\hline $\begin{array}{l}10 \mu \mathrm{m} \text { Gelatine } \\
\text { (cryo-cut) }\end{array}$ & 10.00 & 7.39 & -26.1 & $\begin{array}{c}0.99 \\
(13.4 \%)\end{array}$ \\
\hline $\begin{array}{l}10 \mu \mathrm{m} \text { Gelatine } \\
\text { (laboratory mould) }\end{array}$ & 10.00 & 10.26 & +2.6 & $\begin{array}{c}0.80 \\
(7.8 \%)\end{array}$ \\
\hline $\begin{array}{l}25 \mu \mathrm{m} \text { Gelatine } \\
\text { (commercial mould) }\end{array}$ & 25.00 & 24.90 & -1.0 & $\begin{array}{c}0.59 \\
(2.4 \%)\end{array}$ \\
\hline $\begin{array}{l}30 \text { um Gelatine } \\
\text { (laboratory mould) }\end{array}$ & 30.00 & 28.34 & -5.5 & $\begin{array}{c}1.64 \\
(5.8 \%)\end{array}$ \\
\hline
\end{tabular}

\section{LA-ICP-MS analysis}

A NWR193 Laser Ablation System operated at $40 \mathrm{~Hz}$ (Kenelec Scientific, Frenchs Forest, Australia) was coupled to a 7700series ICP-MS (Agilent Technologies, Mulgrave, Australia) for LA-ICP-MS experiments. Laser and ICP-MS parameters were set to those outlined by Lear et al. to obtain square pixels that represent the same dimensions of the standard ${ }^{29}$ : The laser fluence was set to $0.5 \mathrm{~J} \mathrm{~cm}^{-2}$, the laser beam diameter to $35 \mu \mathrm{m}$, the scan speed to $140 \mu \mathrm{m} \mathrm{s}^{-1}$ and the laser frequency to $40 \mathrm{~Hz}$. Average values, standard deviations and figures of merit were calculated following the abaltion of 4 lines with a length of $2 \mathrm{~mm}$ producing approximately 230 data points per standard and element.

\section{Results and Discussion}

\section{Topography and thickness characterisation}

Mouse lung and muscle were chosen as two representative tissues, which are known to have heterogeneous biochemical distributions of elements and complex physical structures. The topographies of these tissues are shown in Fig. 2. The cryosectioned lung and quadriceps had heterogeneous surfaces due to their native structures and induced artefacts from cryosectioning. Sectioning produced average thicknesses that deviated from the expected values by $49.0 \%$ for lung and $126.4 \%$ for quadriceps tissue. The standard deviation of the thickness was $6.68 \mu \mathrm{m}$ for quadriceps and $2.28 \mu \mathrm{m}$ for lung tissue, which was greater than $50 \%$ of the expected thicknesses. The use of a cryotome to prepare thin standard sections below $50 \mu \mathrm{m}$ inevitably induces artefacts which impact surface roughness, cause thickness anomalies and may change anatomical and elemental distributions. Various types of deformations (homogeneous or differential, isotropic or anisotropic, uniform or non-uniform) were induced by sectioning and several preparation steps (e.g., fixing, drying, shear forces during cutting) ) as discussed by Dorph-Peterson et $a l .{ }^{23}$. These factors are difficult to control or mitigate and lead to a highly heterogeneous physical structure. Modelling these properties by matrix-matched standards is questionable and would produce standards of high heterogeneity and therefore low quality and limited utility. This highlights the dilemma for quantitative elemental bio-imaging - is it possible or even desirable to manufacture representative matrix matched standards for absolute quantification?

Given that most investigations of biological systems require measurement of changes in elemental concentrations relative to a control sample due to a diseased state or treatment regimens, it is more desirable that standards are easily prepared, robust, and reproducible to provide a consistent response, rather than an absolute amount.

Therefore, other materials such as gelatine or homogenised tissues from easily obtainable organs that mimic the physical and biochemical environment is preferable for most applications and has greater potential for harmonised standard 
preparation to improve intra- and inter-laboratory comparisons and reproducibility.

Moulds can be used as an alternative to cryo-sectioning to improve control of thickness and surface roughness. To investigate this, mouse brain and gelatine standards were cryosectioned and compared against gelatine standards that were prepared in both commercial and laboratory-made moulds. The results are shown in Fig. 2 and summarised in Table 1. The cryosectioning of a homogenised brain standard and a gelatine standard resulted in thicknesses of $67.3 \%$ and $73.9 \%$ of the expected value with a standard deviation of $\pm 3.52 \mu \mathrm{m}$ (RSD: $35.2 \%$ ) and $\pm 0.99 \mu \mathrm{m}$ (RSD: $10.0 \%$ ), respectively. High shear forces during sectioning induced surface artefacts and increased thickness at the margins of the sections substantially. Thickness accuracy is also impacted by drying effects of the gelatine which undergoes significant shrinking. In case of a $10 \%$ gelatine material, shrinking can reduce standard thickness by $90 \%$. To avoid gelatine shrinking after cryo-sectioning, gelatine would have to be dried in bulk before freezing and cryosectioning. However, homogeneous drying and controlled shrinking of bulk materials is difficult. In contrast, thin films of gelatine can be dried reproducibly to produce highly defined and homogeneous layers with thicknesses in the lower $\mu \mathrm{m}$ range. In this study, thin films were produced in commercial and laboratory-made moulds. These films had accuracies ranging from $94.5 \%$ to $102.6 \%$ of the expected thickness with typical standard deviation between $0.59 \mu \mathrm{m}$ (RSD: $2.4 \%$ ) and $1.64 \mu \mathrm{m}$ (RSD: $5.5 \%)$. Only the margins of mould-prepared standards appeared to contain drying artefacts, typically seen as an increased thickness.

The precise control of surface flatness and thickness has implications for calibration outcomes; surface roughness increases signal standard deviations and negatively impacts signal precision. Inaccuracies in overall thickness translate directly into systematic errors in quantification when performing complete ablation of a sample. In consideration of the results shown in Fig. 2 and Table 1, surface characterisation of cryo-sectioned standards would be required to ensure they were of expected thickness and free from artefacts potentially inducing systematic and random errors. Otherwise, the concentration can be over- or underestimated substantially as shown for the examples in Fig. 2, where the deviation in height would translate into a concentration error of up to a factor of 2 of the actual value. In contrast, profilometric comparison of
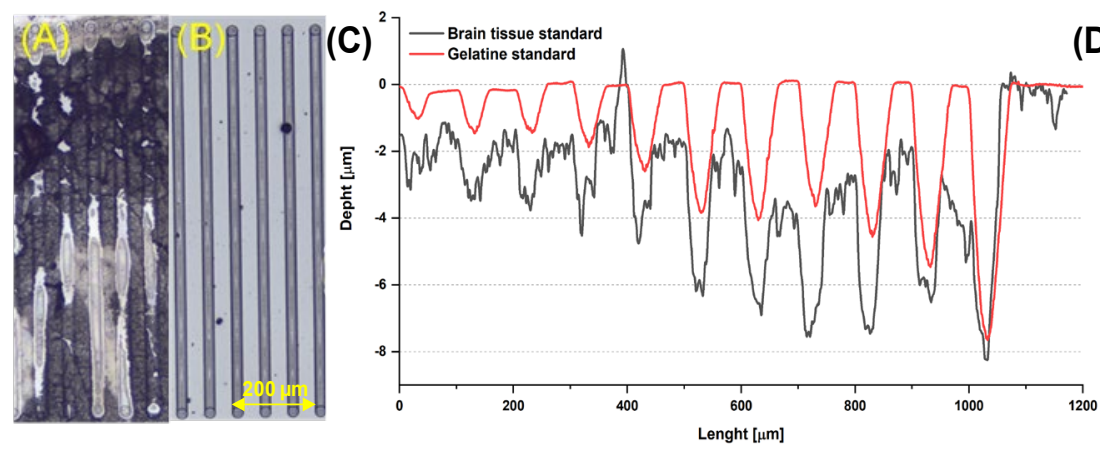

Figure 3: Visual comparison of an ablated homogenised animal tissue standard (A) and a gelatine standard (B). (C): Profilometry data standards ablated eleven times with

increasing laser power. (D): Relative sensitivity for $\mathrm{Mn}, \mathrm{Cu}$, and $\mathrm{Zn}$ derived from repeated ablation of calibration standards.

Table 2: Characterisation of standard materials. The concentrations of each calibration level were cross-quantified by solution-based ICP-MS. LODs, sensitivity and linearity were determined from the calibration curve constructed by LA-ICPMS.

\begin{tabular}{|c|c|c|c|c|}
\hline & & Mn & $\mathrm{Cu}$ & $\mathrm{Zn}$ \\
\hline \multirow{9}{*}{ 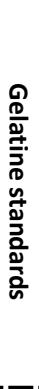 } & Blank $[\mu \mathrm{g} / \mathrm{g}]$ & 2.20 & 0.52 & 0.03 \\
\hline & Level $1[\mu \mathrm{g} / \mathrm{g}]$ & 2.32 & 3.15 & 1.92 \\
\hline & Level 2[ $\mathrm{gg} / \mathrm{g}]$ & 4.30 & 5.00 & 3.97 \\
\hline & 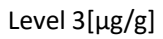 & 7.50 & 9.04 & 6.69 \\
\hline & Level $4[\mu \mathrm{g} / \mathrm{g}]$ & 15.27 & 18.62 & 13.85 \\
\hline & Level $5[\mu \mathrm{g} / \mathrm{g}]$ & 39.39 & 48.85 & 29.33 \\
\hline & LOD $[\mu \mathrm{g} / \mathrm{g}]$ & 1.10 & 4.28 & 0.64 \\
\hline & Linearity $\left(\mathbf{R}^{2}\right)$ & 0.9983 & 0.9916 & 0.9995 \\
\hline & 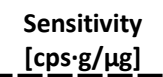 & $1390 \pm 50$ & $143 \pm 5$ & $175 \pm 4$ \\
\hline \multirow{8}{*}{ 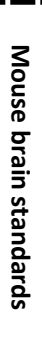 } & Blank & 0.03 & 5.42 & 1.20 \\
\hline & Level $1[\mu \mathrm{g} / \mathrm{g}]$ & 0.53 & 5.49 & 4.17 \\
\hline & Level $2[\mu \mathrm{g} / \mathrm{g}]$ & 10.00 & 15.93 & 18.09 \\
\hline & 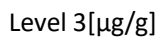 & 29.07 & 38.03 & 33.79 \\
\hline & Level $4[\mu \mathrm{g} / \mathrm{g}]$ & 44.48 & 51.87 & 64.54 \\
\hline & LOD $[\mu \mathrm{g} / \mathrm{g}]$ & 4.18 & 5.39 & 6.41 \\
\hline & Linearity $\left(R^{2}\right)$ & 0.9872 & 0.9941 & 0.9931 \\
\hline & $\begin{array}{l}\text { Sensitivity } \\
\text { [cps.g/ } \mu \mathrm{g}]\end{array}$ & $846 \pm 89$ & $113 \pm 15$ & $194 \pm 14$ \\
\hline
\end{tabular}

sectioned gelatine and mould-prepared gelatine demonstrated an increased control of thickness and reduced surface roughness. Standards were close to the expected thicknesses with superior flatness offering improved quantification and eliminating the requirement for profilometry and cryosectioning.

\section{Post-analysis characterisation}

Fig. 3 (A) shows a micrograph of ablated lines on a homogenised brain standard and (B) on a mould-prepared gelatine standard. Tissue homogenisation resulted in micro-structures with physical properties that caused ablation of the entire standard in some areas, while tissue remained in other areas (Fig. $3(A)$ ). These micro-structured heterogeneities increased the overall error which becomes particularly pronounced when the laser beam spot size is reduced. Micro-structures were not observed in the gelatine standards and ablation produced reproducible patterns (Fig. $3(\mathrm{~B})$ ) with a consistent thickness.

Fig. 3 (C) shows the topography of both homogenised brain

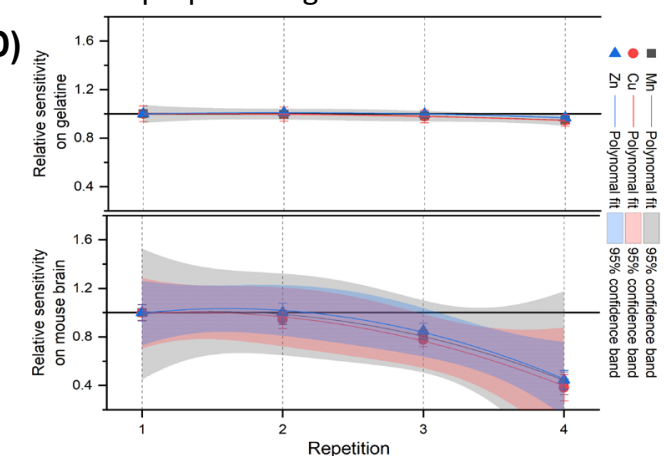


Table 3: Background concentration [pg. $\mathrm{g}^{-1}$ ] of gelatine materials prior and after an additional extraction step with different resins, respectively. Values marked with * were significantly different after removal of background elements determined by application of the t-test at $\alpha=0.05$.

\begin{tabular}{|c|c|c|c|c|c|c|c|}
\hline \multirow[b]{2}{*}{ Gelatine material } & ${ }^{24} \mathrm{Mg}$ & ${ }^{27} \mathrm{Al}$ & ${ }^{55} \mathrm{Mn}$ & ${ }^{56} \mathrm{Fe}$ & ${ }^{58} \mathrm{Ni}$ & ${ }^{63} \mathrm{Cu}$ & ${ }^{66} \mathrm{Zn}$ \\
\hline & & & & & & & \\
\hline Bovine & $40600 \pm 400$ & $21300 \pm 100$ & $2100 \pm 10$ & $54500 \pm 340$ & $338 \pm 9.3$ & $530 \pm 9.4$ & $1200 \pm 120$ \\
\hline Fish & $260 \pm 30$ & $310 \pm 40$ & $8.2 \pm 3.5$ & $910 \pm 52$ & $7.2 \pm 11$ & $120 \pm 10$ & $110 \pm 110$ \\
\hline Porcine & $4500 \pm 200$ & $510 \pm 10$ & $33 \pm 5.9$ & $1300 \pm 98$ & $17 \pm 11$ & $70 \pm 35$ & $300 \pm 170$ \\
\hline \multicolumn{8}{|l|}{ Resin added to porcine gelatine } \\
\hline Amberlite IR120+ ( $\mathrm{Na})$ & $1.7 \pm 2.9 *$ & $330 \pm 99 *$ & $5.7 \pm 0.3$ & $1260 \pm 200$ & $20 \pm 1.1 *$ & $46 \pm 8.9$ & $69 \pm 55$ \\
\hline Amberlite CG-50 (H) & $160 \pm 19 *$ & $260 \pm 170$ & $7.1 \pm 8.0$ & $1000 \pm 340$ & $14 \pm 2.1$ & $260 \pm 4.9$ & $88 \pm 82$ \\
\hline Bio-Rad Bio-Rex-70 (Na) & $12 \pm 21 *$ & $240 \pm 75^{*}$ & $0.4 \pm 0.7$ & $780 \pm 55^{*}$ & $43 \pm 5.8^{*}$ & $76 \pm 3.9$ & $35 \pm 43$ \\
\hline Amberlyst 15 (H) & $140 \pm 52^{*}$ & $250 \pm 63^{*}$ & $0.6 \pm 0.7$ & $670 \pm 24^{*}$ & $4.5 \pm 1.2 *$ & $28 \pm 1.5$ & $33 \pm 57$ \\
\hline
\end{tabular}

thicknesses of $10 \mu \mathrm{m}$. The material ablation behaviour was investigated for both standards using 11 adjacent laser scan lines with increasing laser power, ranging from $0.02 \mathrm{~J} \mathrm{~cm}^{-2}$ to $3.52 \mathrm{~J} \mathrm{~cm}^{-2}$. The ablation of adjacent lines on the homogenised brain standard resulted in crater formation impacting neighbouring scan lines. This uncontrolled removal of surrounding tissue became more prominent with increasing laser power and resulted in increasingly uncontrolled mass flows of ablated elements and decreased spatial resolution. These effects were not observed for gelatine standards improving quantification reliability. The improvement due to increased control of material introduced into the plasma and overall robustness was demonstrated by repeated (four-fold) ablation of a scan line on gelatine and mouse brain standards. The signals of $\mathrm{Mn}, \mathrm{Cu}$ and $\mathrm{Zn}$ as typical biological relevant elements were monitored and their sensitivity (slope of calibration function) was normalised and compared in Fig. 3 (D). The sequential ablation (fluence $0.5 \mathrm{~J} \mathrm{~cm}^{-2}$ ) of gelatine layers resulted in only minor sensitivity drifts, which demonstrates the enhanced ablation and mass flow control. However, the sequential ablation of layers on homogenised brain standards resulted in significant drifts, a direct consequence of poorly controlled ablation and heterogeneity in surface and structure.

\section{Analytical figures of merit and background equivalent concentrations}

The analytical figures of merit were compared between calibrations of gelatine and homogenised brain standards. The actual concentration of the biologically relevant elements $\mathrm{Mn}$, $\mathrm{Cu}$ and $\mathrm{Zn}$ were determined by solution nebulisation ICP-MS and are shown in Table 2 together with resulting limits of detection (LODs), Pearson $R^{2}$ values (for linearity) and sensitivities obtained from the calibration curves following LAICP-MS analysis. When compared to tissue standards, LODs for gelatine standards were 10-times lower for $\mathrm{Zn}$, 3.8-times lower for $\mathrm{Mn}$ and only slightly reduced for $\mathrm{Cu}$. The sensitivities were similar for $\mathrm{Cu}$ and $\mathrm{Zn}$ in both gelatine (Cu: $143 \mathrm{cps} \mathrm{g} \mathrm{\mu g}^{-1}$;

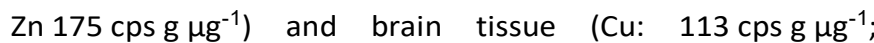
$\mathrm{Zn} 194 \mathrm{cps} \mathrm{g} \mathrm{gg}^{-1}$ ) and increased for $\mathrm{Mn}$ in gelatine (1390 vs.

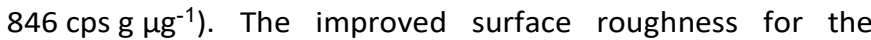
gelatine standards resulted in decreased standard deviation of sensitivity (i.e. the standard deviation of the slope) for all elements. The gelatine also contained lower background levels of biologically relevant elements (except $\mathrm{Mn}$ ) than homogenised brain.

Background concentrations of elements in standard matrices confound LODs achievable via external calibration and need to be minimised to measure elements that are at low concentrations or may be downregulated due to metal dyshomeostasis. Accordingly, three different gelatine types were investigated for background concentrations of various metals shown in Table 3.

Fish and porcine gelatine contained the lowest levels, which would make these materials favourable for lower LODs. However, from these two, only porcine gelatine formed a solid gel at room temperature when using $10 \%$ solutions. The background levels were further reduced with a solid-liquid extraction step during standard preparation. Porcine standards were heated until liquefied and spiked with ion exchange resins, which were subsequently separated from the gelatine via centrifugation. Five different resins were evaluated to reduce metal levels in the porcine gelatine standards. The addition of resins required effective buffering of the gelatine solutions due to $\mathrm{pH}$ changes affecting gelatine integrity. The use of extraction resins reduced the natural background levels of all gelatine types crucially. Table 3 shows the background levels of elements that are naturally present in gelatine and highlights the efficacy of using extraction resins to reduce their abundance to a level that will allow the quantification of biologically relevant trace elements.

\section{Conclusion}

The analysis of lung and quadriceps tissue via LA-ICP-MS samples demonstrated the complex requirements and limitations of matrix-matching definitive external calibration standards. Their adequate preparation is questionable and may produce standards with poor precision, accuracy and reproducibility. Employing gelatine as a standard matrix mimics the most important physical and biochemical properties of biological tissue sections, and allowed facile preparation with increased control of the physical properties and elemental 
backgrounds resulting in improved ablation characteristics in LA-ICP-MS.

The preparation of gelatine standards by using moulds rather than cryo-sectioning improved accuracy, precision and robustness for reproducible quantification and analytical figures of merit. Compared to homogenised brain standards, mould-prepared gelatine standards were easier to prepare and had greater control of standard manufacture, which resulted in improved robustness and analytical figures of merit. The figures of merit depended on naturally abundant elements in the gelatine. The background concentration of elements deviated significantly between different sources of gelatine. The source of the gelatine should be considered to enable reliable low level calibration for metals which are downregulated by a biological response.

The dynamic calibration range was further improved for gelatine standards employing an additional metal extraction step during standard preparation using various resins. All five resins allowed elemental background reduction improving limits of detection.

These methods to manufacture gelatine films advance standard preparation for LA-ICP-MS. Due to their facile production and improved properties, they have potential to improve intra- and inter-laboratory comparability for standard harmonisation.

\section{Ethical statement}

Animal procedures were performed in accordance with the Guidelines for Care and Use of Laboratory Animals and approved by the Animal Ethics Committee of the Florey Institute of Neuroscience and Mental Health (Melbourne, Australia) (approval \#15-104-FINMH) and the Institutional Animal Care and Use Committee at the University of California (Los Angeles, USA) (ARC \#2000-029-61D).

\section{Conflicts of interest}

There are no conflicts of interest to declare.

\section{Acknowledgements}

TEL is supported by the Australian Government Research Training Program Scholarship.

AR is the recipient of the PROMOS scholarship of the German Academic Exchange Service (DAAD).

DPB is supported by an Australian Research Council Discovery Early Career Researcher Award DE180100194.

PAD is the recipient of Australian Research Council Discovery Projects DP170100036 and DP190102361.

DC is funded by the Deutsche Forschungsgemeinschaft (DFG, German Research Foundation) - 417283954.

\section{References}

1

S. Wang, R. Brown and D. J. Gray, Appl. Spectrosc., 1994, 48 , 1321-1325.

J. Seuma, J. Bunch, A. Cox, C. McLeod, J. Bell and C. Murray, Proteomics, 2008, 8, 3775-3784.

R. González de Vega, D. Clases, M. L. Fernández-Sánchez, N. Eiró, L. O. González, F. J. Vizoso, P. A. Doble and A. SanzMedel, Anal. Bioanal. Chem., 2019, 411, 639-646.

D. Günther and B. Hattendorf, TrAC Trends Anal. Chem., 2005, 24, 255-265.

5 B. Fernández, P. Rodríguez-González, J. I. García Alonso, J. Malherbe, S. García-Fonseca, R. Pereiro and A. Sanz-Medel, Anal. Chim. Acta, 2014, 851, 64-71.

D. Clases, R. Gonzalez de Vega, P. A. Adlard and P. A. Doble, J. Anal. At. Spectrom., 2019, 34, 407-412.

A. Limbeck, P. Galler, M. Bonta, G. Bauer, W. Nischkauer and F. Vanhaecke, Anal. Bioanal. Chem., 2015, 407, 6593-6617. M. Bonta and H. Lohninger, Analyst, 2014, 139, 1521-31. D. Clases, R. Gonzalez de Vega, D. Bishop and P. Doble, Anal. Bioanal. Chem., 2019, 411, 3553-3560.

D. Hare, C. Austin and P. Doble, Analyst, 2012, 137, 15271537.

D. Hare, J. Lear, D. Bishop, A. Beavis and P. A. Doble, Anal. Methods, 2013, 5, 1915-1921.

D. Hare, C. Austin, P. Doble and M. Arora, J. Dent., 2011, 39, 397-403.

R. González de Vega, M. L. Fernández-Sánchez, J. Pisonero, N. Eiró, F. J. Vizoso and A. Sanz-Medel, J. Anal. At. Spectrom., 2017, 32, 671-677.

D. Clases, S. Fingerhut, A. Jeibmann, M. Sperling, P. Doble and U. Karst, J. Trace Elem. Med. Biol., 2019, 51, 212-218. R. Niehaus, M. Sperling and U. Karst, J. Anal. At. Spectrom., 2015, 30, 2056-2065.

D. Hare, E. P. Raven, B. R. Roberts, M. Bogeski, S. D. Portbury, C. A. McLean, C. L. Masters, J. R. Connor, A. I. Bush, P. J. Crouch and P. A. Doble, Neuroimage, 2016, 137, 124131.

S. Rodríguez-Menéndez, B. Fernández, M. García, L. Álvarez, M. Luisa Fernández, A. Sanz-Medel, M. Coca-Prados, R. Pereiro and H. González-Iglesias, Talanta, 2018, 178, 222 230.

H. González-Iglesias, C. Petrash, S. Rodríguez-Menéndez, M. García, L. Álvarez, L. Fernández-Vega Cueto, B. Fernández, R. Pereiro, A. Sanz-Medel and M. Coca-Prados, J. Anal. At. Spectrom., 2017, 32, 1746-1756.

O. Reifschneider, C. A. Wehe, K. Diebold, C. Becker, M. Sperling and U. Karst, J. Anal. At. Spectrom., 2013, 28, 989993.

O. Hachmöller, M. Aichler, K. Schwamborn, L. Lutz, M. Werner, M. Sperling, A. Walch and U. Karst, J. Trace Elem. Med. Biol., 2016, 35, 97-102.

M.-M. Pornwilard, M. Uta, R. Weiskirchen and J. S. Becker, Int. J. Mass Spectrom., 2013, 354-355, 281-287. M. Arora, D. Hare, C. Austin, D. R. Smith and P. Doble, Sci. Total Environ., 2011, 409, 1315-1319. 
Gundersen, J. Microsc., 2001, 204, 232-246. M. Šala, V. S. Šelih and J. van Elteren, Analyst, 2017, 142, 3356-3359.

25 A.-C. Niehoff, J. Grünebaum, A. Moosmann, D. Mulac, J. Söbbing, R. Niehaus, R. Buchholz, S. Kröger, A. Wiehe, S. Wagner, M. Sperling, H. von Briesen, K. Langer and U. Karst, Anal. Chim. Acta, 2016, 938, 106-113. H. Sela, Z. Karpas, H. Cohen, Y. Zakon and Y. Zeiri, Int. J. Mass Spectrom., 2011, 307, 142-148. D. Gholap, J. Verhulst, W. Ceelen and F. Vanhaecke, Anal. Bioanal. Chem., 2012, 402, 2121-2129. M. Birka, K. S. Wentker, E. Lusmöller, B. Arheilger, C. A. Wehe, M. Sperling, R. Stadler and U. Karst, Anal. Chem., 2015, 87, 3321-3328.

29 J. Lear, D. J. Hare, F. Fryer, P. A. Adlard, D. I. Finkelstein and P. A. Doble, Anal. Chem., 2012, 84, 6707-14. 